\title{
Outcome of patients with placenta accreta at el shatby maternity university hospital
}

\begin{abstract}
Background: Placenta accreta occurs when the placental implantation is abnormal. The marked increase in incidence has been attributed to the increasing prevalence of cesarean delivery in recent years. The most common theory is that defective decidualization. The most important risk factor for placenta accreta is placenta previa after a prior cesarean delivery. The first clinical manifestation of placenta accreta is usually profuse, lifethreatening hemorrhage. The recommended management of suspected placenta accreta is planned preterm cesarean hysterectomy with the placenta left in situ.
\end{abstract}

Patients and methods: It's a study of all cases of placenta accreta at El-Shatby Maternity University Hospital starting from 1/4/2016 till 1/10/2016. Selection of the cases will only be dependent upon their pregnancy gestational age above 28 weeks of gestation.

Results: The incidence of placenta accreta was $1 / 75$ cesarean deliveries. The ultrasonography and doppler had a false negative rate of (54.6\%) and a sensitivity of $(45.2 \%)$ in diagnosis of placenta accreta. The rate of blood transfusion was $(79.6 \%)$. Uterine preserving procedures performed in $(66 \%)$. Cesarean hysterectomy performed in $(34 \%)$. Intensive care unit admission occurred in $(27.3 \%)$. The mean gestational age at delivery was $33.8 \pm 4.6$ weeks gestation. (31.8\%) admitted to the neonatal intensive care unit.

Conclusion: The incidence of placenta accreta increased due to the increasing rate of cesarean deliveries, prenatal diagnosis of placenta accreta is paramount, as most women are asymptomatic. Prenatal diagnosis allows time for a multidisciplinary team to make delivery plans, which will help decrease surgical complications.
Volume 8 Issue 2 - 2017

\section{Eman Ali Abd Elfatah, Elsayed Elbadwy Mohamed Awad, Tamer MamdouhAbd- Eldaym, Zynb Hassan Ali}

Department of Obstetrics and Gynecology, Alexandria University, Egypt

Correspondence: Eman Abd El Fattah, Department of Obstetrics and Gynecology, Faculty of Medicine, Alexandria University, Egypt, Email eman0eman0eman7@gmail.com

Received: March 10,2017 | Published: October 27, 2017

\section{Introduction}

Placenta accreta occurs when the placental implantation is abnormal: the decidua basalis that normally separates the anchoring villi and the myometrium is missing. ${ }^{1}$ The incidence of placenta accreta appears to be increasing. In 1950s, placenta accreta was rare, occurring in 1 in 30,000 deliveries. In 1970s, the incidence was estimated to be 1 in 4,027 deliveries. In 1980s, the incidence increased to be 1 in $2,510 .{ }^{2}$ For the period of 1982-2002, researchers have reported the incidence of placenta accreta as 1 in 533 deliveries. ${ }^{3}$ In 2006, the incidence increased to be 1 in 210 deliveries. ${ }^{4}$ The pathogenesis of placenta accreta is not known with certainty. The most common theory is defective decidualization (thin, poorly formed, or absent decidua) related to previous surgery or to anatomical factors (endocervix, lower uterine 2 segment, endosalpinx, uterine anomaly) allows the placenta to attach directly to the myometrium. ${ }^{5,6}$ The most important risk factor for placenta accreta is placenta previa after a prior cesarean delivery. Other risk factors for placenta accreta include: uterine instrumentation, intrauterine scarring, smoking, maternal age over 35 , grand multiparity, and recurrent miscarriage. ${ }^{7,8}$ The first clinical manifestation of placenta accreta is usually profuse, life-threatening hemorrhage that occurs at the time of attempted manual placental separation. Poorly controlled hemorrhage related to placenta accreta, increta and percreta is the indication for one to two thirds of peripartum hysterectomies, ${ }^{9}$ disseminated intravascular coagulopathy, adult respiratory distress syndrome, renal failure, unplanned surgery, and death. ${ }^{10}$ The diagnosis is made by (2D) gray scale ultrasound, three dimentional ultrasound, color doppler ultrasound and magnetic resonance imaging. ${ }^{11}$ The timing of delivery in cases of suspected placenta accreta is preterm elective CS at 35-36 weeks. ${ }^{12}$ Generally, the recommended management of suspected placenta accreta is planned preterm cesarean hysterectomy with the placenta left in situ because removal of the placenta is associated with significant hemorrhagic morbidity. ${ }^{2}$ Women, who have a strong desire for future fertility uterine sparing approaches may be used as methotrexate, local resection of placental implantation site, systematic pelvic devascularization, uterine tamponade, and interventional radiology with internal iliac artery ligation, but these approaches may be complicated by sepsis, hemorrhage, ${ }^{13}$ and hysterectomy can become necessary.

\section{Patients and methods}

Patients included had ultrasound signs suggestive of placenta accreta, previous cesarean section with placenta implanted over the scar and suggestive ultrasonographic signs, and MRI signs of placenta accreta. Patients with average gestational age below 28 weeks were excluded. All cases were subjected to thorough history taking, complete general examination, and investigations. Documentation of interventions performed, maternal outcome, and fetal outcome was done.

\section{Results}

The incidence of placenta accrete was 1 in 75 cesarean deliveries (Table 1). The mean age of included women with placenta previa was $26.7 \pm 4.9$ years (range: $21-32$ years). The mean gestational age at delivery was $33.8 \pm 4.6$ weeks' gestation (range: 29 - 39 weeks' gestation) (Table 2). The median parity was 3 (range: 1 - 5; interquartile range: 2 -4). All the included cases had at least one previous CS (Table 3). Of the included 44 women with morbidlyadherent placenta previa, $24(54.6 \%)$ presented with antepartum hemorrhage (Table 4). Antenatal ultrasonography was suggestive 
of placenta accreta in only 20 cases (resulting in a false negative rate of 54.6\%) (Table 5). Intraoperatively, balloon catheterization was done in 0 cases $(0 \%)$. Uterine artery ligation was performed in $24(54.5 \%)$ cases, and internal iliac artery ligation in $4(9.1 \%)$ cases. Hysterectomy was performed in $15(34.1 \%)$ cases, only 3 $(6.8 \%)$ were total hysterectomy. Bladder injury was encountered in $9(20.5 \%)$ cases. compression sutures were performed in $28(63.6 \%)$ cases (Table 6). The median estimated intraoperative blood loss was $2.5 \mathrm{~L}$ (range: $1-5 \mathrm{~L}$; interquartile range: $2-3 \mathrm{~L}$ ). The overall rate of blood transfusion in included women was 35/44 (79.6\%). The median was 3 units (range: 1-5 units; interquartile range: 2-4 units). The overall rate of FFP transfusion was 35/44 (79.6\%). The median was 3 units (range: 1-5 units; interquartile range: 1-4 units). Only $1(2.3 \%)$ woman received platelet transfusion and only $1(2.3 \%)$ woman received cryoprecipitate transfusion (Table 7). Of the included 44 women, 3 (6.8\%) developed DIC, $12(27.3 \%)$ were admitted to ICU postoperatively, Only $1(2.3 \%)$ patient was readmitted because of developing postoperative collection. $3(6.8 \%)$ were re-operated upon (for postpartum collapse and intraabdominal bleeding). One case of maternal death (Table 8) was there. The median hospital stay after delivery was 3 days (range: 2-5 days; interquartile range: $2.5-$ 4 days).Of the included 44 neonates, $23(52.3 \%)$ were males, while $21(47.7 \%)$ were females. The median birth weight was $2734 \mathrm{~g}$ (range: 700 - $4500 \mathrm{~g}$; interquartile range: $1388-3605 \mathrm{~g}$ ). The median 1-min Apgar score was 4 (range: 1 - 9; interquartile range: 3 - 7). The median 5-min Apgar score was 5 (range: 3 - 9; IQR: 4 - 7) (Table 9).

Table I Incidence of morbidly-adherent placenta previa cases in relation to total no. of cesarean deliveries during the studied period $(n=44)$

\begin{tabular}{lll}
\hline & No. & $\%$ \\
\hline CS & 3300 & 100 \\
Placenta Accreta & 44 & 1.3 \\
\hline
\end{tabular}

Table 2 Demographic data of women with morbidly-adherent placenta previaduring the studied period

\begin{tabular}{lll}
\hline & Range & Mean \pm SD \\
\hline Age (Years) & $21-32$ & $26.7 \pm 4.9$ \\
Gestational Age (Weeks) & $29-39$ & $33.8 \pm 4.6$
\end{tabular}

Table 3 No. of previous CS in women with morbidly-adherent placenta previaduring the studied period $(n=44)$

\begin{tabular}{lll}
\hline & Range & Mean \pm SD \\
\hline Parity & & \\
Range & I -5 & \\
Median (IQR) & $3(2-4)$ & \\
Previous CS & & \\
I & 13 & 29.6 \\
2 & 16 & 36.4 \\
3 & 8 & 18.2 \\
4 & 6 & 13.6 \\
5 & 1 & 2.3 \\
\hline
\end{tabular}

Table $4 \mathrm{APH}$ as the presenting complaint in included women with morbidly adherent placenta previa during the studied period $(n=44)$

\begin{tabular}{lll}
\hline APH & No & $\%$ \\
\hline Yes & 24 & 54.6 \\
No & 20 & 45.5 \\
\hline
\end{tabular}

Table 5 Sonographic prediction of morbid placental adherence in included women with morbidly-adherent placenta previa $(n=44)$

\begin{tabular}{lll}
\hline Antenatal Ultrasonography & No & $\%$ \\
\hline High possibility of placenta accrete & 20 & 45.5 \\
Low possibility of placenta accreta & 24 & 54.6 \\
\hline
\end{tabular}

Table 6 Surgical management and intraoperative findings in included women with morbidly-adherent placenta previa $(n=44)$

\begin{tabular}{lll}
\hline & No & $\%$ \\
\hline Balloon catheterization & 0 & 0 \\
Bilateral uterine artery ligation & 24 & 54.5 \\
Internal Iliac Artery Ligation & 4 & 9.1 \\
Hysterectomy & 15 & 34.1 \\
Total hystrectomy & 3 & 6.8 \\
SubTotalhystrectomy & 12 & 27.3 \\
Bladder Injury & 9 & 20.5 \\
Compression sutures & 28 & 63.6 \\
\hline
\end{tabular}

Table 7 Estimated Intraoperative Blood Loss and Blood Transfusion in Included Women with Morbidly-Adherent Placenta Previa during the Studied period $(n=44)$

\begin{tabular}{lll}
\hline & No & $\%$ \\
\hline Estimated Blood Loss(L) & & \\
Range & I- 5 & \\
Median (IQR) & $2.5(2-3)$ & \\
Blood Transfusion & 35 & 79.6 \\
Range & I- & \\
Median (IQR) & $3(2-4)$ & \\
FFP Transfusion & 35 & 79.6 \\
Range I - 5 Median (IQR) & I- 5 & \\
Platelet Transfusion & $3($ I- 4) & \\
Cryoprecipitate Transfusion & I & 2.3 \\
\hline
\end{tabular}

Table 8 Postoperative findings in Included Women with Morbidly-Adherent Placenta $(n=44)$

\begin{tabular}{lll}
\hline & No & $\%$ \\
\hline DIC & 3 & 6.8 \\
ICU admission & 12 & 27.3 \\
Reoperation & 3 & 6.8 \\
Readmission & $\mathrm{I}$ & 2.3 \\
Duration of hospital stay (days) & & \\
Range & $2-5$ & \\
Median (IQR) & $3(2.5-4)$ & \\
Death & $\mathrm{I}$ & 2.3
\end{tabular}

Table 9 Neonatal Outcome in Included Women with Morbidly-Adherent Placenta $(n=44)$

\begin{tabular}{lll}
\hline Neonatal gender & No & $\%$ \\
\hline Male & 23 & 52.3 \\
Female & $2 \mathrm{I}$ & 47.7 \\
Intrauterine fetal death & $\mathrm{I}$ & 2.3 \\
NICU admission & $\mathrm{I} 4$ & 31.8 \\
Birth Weight (g) Range & $700-4500$ & \\
Median (IQR) & $2736(1388-3605)$ \\
I $^{\text {st }}$ min APGAR Score & \\
Range & $\mathrm{I}-9$ & \\
Median (IQR) & $4(3-7)$ & \\
& & \\
$\mathbf{5}^{\text {th }}$ min APGAR Score & & \\
Range & $3-9$ & \\
Median (IQR) & $5(4-7)$ & \\
\hline
\end{tabular}




\section{Discussion}

Over a 6 months period there were 3300 cesarean deliveries and a 44 cases diagnosed as having placenta accreta. The incidence of placenta accreta was 1/75 cesarean deliveries. Compared with the literature which reports that the incidence of placenta accreta in 2006 was $1 / 210$ deliveries. ${ }^{4}$ The incidence of placenta accreta at El-Shatby Maternity University Hospital is increased because it's a tertiary referral centre for three governorates. In our study all the included cases had at least one previous CS, number of patients with placenta previa and a history of one, two, three, four and five cesarean section delivery were $729.6 \%, 36.4 \%, 18.2 \%, 13.6 \%$ and $2.3 \%$ cases, respectively. None of patients were with a history of more than five cesarean section delivery. Of the 44 patients in the current study, the mean age of included women with morbidly adherent placenta was $26.7 \pm 4.9$ years (range: $21-32$ years). Of the included 44 women with morbidly-adherent placenta previa, 24 (54.6\%) presented with $\mathrm{APH}$. According to the current study the antenatal ultrasonography and doppler was suggestive of morbid adherence in only 20 cases (resulting in a false negative rate of $54.6 \%$ and a sensitivity of $45.5 \%$ ). This may be due to the fact that most ultrasonic examinations were performed by emergency department doctors with limited experience. Although there still appears to be a difference of opinion in the literature regarding the accuracy of ultrasound for the diagnosis of placenta accrete. With the exception of the Lam study who reports a sensitivity of $33 \%,{ }^{14}$ all other studies report a sensitivity of 77 $93 \% .^{14,15}$ Morbidity from placenta accreta is caused by problems associated with massive bleeding. In the present study, the median estimated intraoperative blood loss was $2.5 \mathrm{~L}$ (range: 1 - $5 \mathrm{~L}$; IQR: $2-3 \mathrm{~L}$ ). The overall rate of blood transfusion in included women was 35/44 (79.6.8\%) (range: 1-5 units ). The overall rate of FFP transfusion was 35/96 (79.6\%) (range: $1-5$ units). Only 1 (2.3\%) woman received platelet transfusion and only $1(2.3 \%)$ woman received cryoprecipitate transfusion. The present findings are similar to other reported rates of transfusion. For example a more recent study, which analyzed 99 placenta accreta cases, found that approximately $75 \%$ required blood transfusion with a mean of $5.4 \pm 2.1$ units of RBCs. ${ }^{16}$ Thus, blood transfusion should be anticipated, and massive transfusion is not rare in these obstetric patients. Other causes of early morbidity (coagulopathy, admission to the intensive care units, bladder injury $\&$ early reoperation) are also high in patients with placenta accreta, as reported in previous study. ${ }^{10}$ In the current study 3 of the 44 patients had DIC and admitted to the ICU $(6.8 \%), 12$ were admitted to ICU postoperatively. The duration of ICU admission range from 2 to 5 days. In terms of maternal morbidity, 15 cases $(34.1 \%)$ underwent a cesarean hysterectomy. Three of them were total hysterectomy while the majority ( 9 cases) were subtotal hysterectomy. Uterine preserving procedures were done in 32 cases, 24 cases by uterine artery ligation, 4 cases out of the 24 cases were accompanied by internal iliac artery ligation, and 28 cases by compression sutures. Of the 44 patients, 1 case required readmission, complaining of post-operative collection, 3 cases needed reoperation ( 2 cases to control bleeding while the third with a missed bladder injury). Maternal mortality has been reported in up to $7 \%$ of cases. ${ }^{17}$ In the current study there was one maternal death $(2.7 \%)$ only because of better care in our hospital. In cases of placenta accreta the incidence of perinatal complications is also increased mainly due to preterm birth and small for gestational age fetuses. ${ }^{10}$ In the present study, the mean gestational age at delivery was $33.8 \pm$ 4.6 weeks' gestation (range: 29 - 39 weeks' gestation). The median birth weight was $2800 \mathrm{~g}$ (range: 700 - 4500g; IQR: 1388 - $3605 \mathrm{~g}$ ). James reported that the sex ratio associated with placenta accreta favors females. in the present study, Of the included 44 neonates, 23
$(52.3 \%)$ were males, while $21(47.7 \%)$ were females. So, the result of the current study is opposite to the result of the previous literature. The median 1-min Apgar score was 4 (range: 1 - 9; IQR: 3 - 7) and median 5-min Apgar score was 5 (range: 3 - 9; IQR: 4 - 7). 14 infants were admitted to the neonatal intensive care unit (NICU). Neonatal outcome in the current study was uniformly good according to median birth weight and the median 5-min Apgar score.

\section{Acknowledgments}

None.

\section{Conflicts of Interest}

Authors declare that they have no conflict of interest.

\section{References}

1. Esh Broder E, Ariel I, Abas Bashir N, Placenta accreta is associated with IVF pregnancies: a retrospective chart review. BJOG. 2011;118(9):1084 1089.

2. ACOG Placenta accrete. Committee Opinion No. 529. American College of Obstetricians and Gynecologists. Obstet Gynecol. 2012;120:207-211.

3. Wu S, Kocherginsky M, Hibbard JU. Abnormal placentation: twentyyear analysis. Am J Obstet Gynecol. 2005;192:1450-1461.

4. Stafford I, Belfort M. Placenta accreta, increta, and percreta: a teambased approach starts with prevention. Contemp Ob Gyn. 2008;53(4):7682.

5. TantbirojnP, Crum CP, Parast. Pathophysiology of placenta creta: the role of deciduaand extravilloustrophoblast. Placenta. 2008;29(7):639645

6. Khong TY. The pathology of placenta accreta, a worldwide epidemic. $J$ Clin Pathol. 2008;61(12):1243.

7. ACOG Committee. ACOG Committee Opinion No. 266. January 2002 Placenta accreta American College of Obstetricians and Gynecologists. Obstet Gynecol. 2002;99(1):169-170.

8. Gielchinsky Y, Rojansky N, Fasouliotis SJ, et al. Placenta accreta: summary of 10 years: a survey of 310 cases. Placenta. 2002;23(23):210-214

9. Glaze S, Ekwalanga P, Roberts G, et al. Peripartum hysterectomy: 1999 to 2006. Obstet Gynecol. 2008;111(3):732-738.

10. Eller AG, Porter TF, Soisson P, et al. Optimal management strategies for placenta accreta. BJOG. 2009;116(5):648-654

11. Shih JC, Palacios Jaraquemada JM, Su YN, et al. Role of threedimensional power Doppler in the antenatal diagnosis of placenta accreta: comparison with gray scale and color Doppler techniques. Ultrasound Obstet Gynecol. 2009;33(2):193-204.

12. Royal College of Obstetricians and Gynaecologists. Placenta praevia placenta praeviaaccreta and vasa praevia: diagnosis and management. 2011 .

13. Butt K, Gagnon A, Delisle MF.Failure of methotrexate and internal iliac balloon catheterization to manage placenta percreta. Obstet Gynecol. 2002;99:981-982.

14. Lam G, Kuller J, Mc Mahon M. Use of magnetic resonance imaging and ultrasound in the antenatal diagnosis of placenta accreta. J Soc Gynecol Investig. 2002;9(1):37-40.

15. Warshak CR, Eskander R, Hull AD, et al. Accuracy of ultrasonography and magnetic resonance imaging in the diagnosis of placenta accreta. Obstet Gynecol. 2006;108(3):573-581. 
16. Warshak CR, Ramos GA, Eskander R, et al. Effect of predelivery diagnosis in 99 consecutive cases of placenta accreta. Obstet Gynecol. 2010;115(1):65-69.
17. Cooper, Anne Colleen. The Rate Of Placenta Accreta and Previous Exposure To Uterine Surgery. Yale Medicine Thesis Digital Library. 2012;p.1702. 